\title{
A CASE FOR REVISITING DEFINITIONS OF SERIAL VERB CONSTRUCTIONS- EVIDENCE FROM AKAN SERIAL VERB NOMINALIZATION
}

\author{
Obadele Kambon, E. Kweku Osam, Nana Aba Appiah Amfo \\ University of Ghana - Legon
}

\begin{abstract}
In this study, we undertook an experiment in which native speakers of Akan were given serial verbs both with and without oblique non-verbal elements (such as relator nouns, direct objects, postpositions, etc.) and asked them to construct Serial Verb Construction Nominals (SVCNs) from them. We found that, by and large, when not given said nonverbal elements, speakers were not able to construct nominal forms. In another task, we gave speakers nominal forms and asked them to deconstruct them to the constituent serial verbs from which they were derived. Time and again, speakers gave, not only the serial verbs, but also the non-verbal elements even though they were not asked to do so. Gestalt meanings were also given by speakers when asked the meanings of individual elements. Thus, the semantic integration and lexicalization that takes place in full lexicalizedintegrated serial verb constructions extends not only to serial verbs but also to these nonverbal elements which, to native speakers, seem to form just as important a part of the SVC as the verbal elements. Thus, we argue that definitions of SVCs, henceforth, should not prejudice the serial verbs to the detriment of other equally important parts of the construction.
\end{abstract}

Key words: Serial verbs constructions (SVCs), Serial Verb Construction Nominalization / Nominal (SVCN), semantic integration, composition, decomposition.

\section{Introduction}

This paper attempts to capture what native speakers of Akan, a serializing language, know about their language and to see how that knowledge may have implications for how Serial Verb Constructions (SVCs) are understood in the language and defined in the literature. To that end, we will look at how those SVCs that include non-verbal elements - about $20 \%$ of all Full LexicalizedIntegrated Serial Verb Constructions (FL-ISVCs) identified - are nominalized by native speakers when these speakers are provided with the non-verbal elements for the task vs. when those nonverbal elements are withheld. The hope is that nominalization of SVCs may provide a window into the role semantic integration and lexicalization play in how important non-verbal elements are in the accomplishment of the nominalization task and in Akan FL-ISVCs in general. We also look at what speakers do when requested to decompose an instantiation of Serial Verb Construction Nominalization (SVCN) into its constituent serial verbs and how non-verbal elements may figure into that task as well. Thus, we are attempting to use nominalization to get an understanding of the significance of non-verbal elements in Akan Serial Verb Constructions (SVCs). This research question is important because the literature tends to define SVCs in such a way that non-verbal elements are entirely missing from the discussion. Consider Aikhenvald's (2006:1) definition of SVCs as "a sequence of verbs which act together as a single predicate, without any overt marker of coordination, subordination, or syntactic dependency of any other sort." Also consider Durie (1997:289-290) defining archetypal SVCs as consisting "of a sequence of two or more verbs 
which in various (rather strong) senses, together act like a single verb." What is common to these definitions is the lack of discussion of complements or arguments of the verbs which make up the SVC. We find that when non-verbal elements of the SVC are mentioned, it tends to be within the context of the contiguity of verbal elements, specifically the obligatory (or non-obligatory) nature of argument sharing (Baker 1989; Bodomo and Oostendorp 1994; Bodomo 2004; Aikhenvald and Dixon 2006; Bodomo 2006; Hiraiwa and Bodomo 2008).In dealing specifically with the contiguity of elements within the SVCN utilizing data from Dàgáárè, Bodomo $(2004 ; 2006: 6)$ makes the following point:

It seems that for one reason or another, the verbs have to be obligatorily adjacent in these constructions. This is a first indication by the facts of SVCN in support of our theoretical analysis of serial verb constructions as complex predicates which undergo syntactic operations as a single unit (Bodomo 2006:6).

Bodomo cites the following Dàgáárè data to make his case:

(1) à néǹ dóg óó-ó

DEF meat boil chew-NOM

'The cook chewing of the meat.'

(i.e. 'The cooking of the meat in order to eat')

(2)
a. à tàngmà zò gààdí-íú
DEF shea fruit.PL run go eat-NOM
'The run go eating of the shea fruits.'
(i.e. 'Running there in order to eat the shea fruits')
b. *à zò gàà tàngmà dínú
c. *à zò tàńgmà gàà dííú

Bodomo states:
In nominalizing serial verb constructions in Dàgáárè, the last of the series of verbs gets the nominalized suffix. If there is a direct object to the last verb, it can only occur at the outer left of the verbal cluster" (Bodomo 2006:5).

However, we see here, in the case of mpaemuka in Akan that the DO can remain in its prenominalized position indicating that Bodomo's observations are not universal.

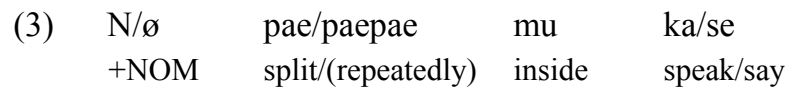

SVCN: mpaemuka, etc. 'open confession'

While the facts of Dàgáárè are not overtly stated to be universal, this counterexample from Akan does have implications for Bodomo's use of contiguity as the basis of an analysis that complex predicates undergo operations as a single unit cross-linguistically. According to Bodomo, 
These issues have been addressed with data mainly from Dagaare, but it is expected that data from other serialization and other complex language predicate languages would illustrate similar phenomena (Bodomo 2006:16).

Contiguity, while common in FL-ISVC nominalization in serializing languages, is not the absolute rule for all of them as illustrated here by the case of mpaemuka. It is also worth noting that mpaemuka could be viewed as example of collocation between pae and its internal argument $m u$ before the introduction of V2 $\mathrm{ka}$ in the serial verb construction.

This example is also relevant in that it shows that true complement NPs, PPs, etc., can be incorporated into the SVCN. In sentential form, the SVC would appear as:

$$
\begin{aligned}
& \text { Pae mu ka! } \\
& \text { split inside } \\
& \text { 'Coneak } \\
& \text { Confess openly!' }
\end{aligned}
$$

We also see intervening elements incorporated in the SVC twa...ho...hyia, which is nominalized as ntwahohyia 'circumference'.

$$
\begin{aligned}
& \mathrm{N} \text { twa ho hyia } \\
& \text { +NOM cut/cross body meet } \\
& \text { SVCN: } \text { ntwahohyia 'circumference' }
\end{aligned}
$$

Again, this has implications for Bodomo's analysis and is also relevant to the current discussion which argues that all semantically integrated elements of the SVC are important to native speakers as seen through how they are indispensable to the nominalization process. Other examples of true complement incorporation in the SVCN can be found in
(6)
a wu $\mathrm{N}$ gya (a)de( $(\varepsilon)$
+ NOM die ? leave thing
SVCN: awunnyade( $\varepsilon$ ) 'inheritance'

This SVCN is defined in Christaller as ade a obi awu de agyaw wo 'a thing that someone who has died leaves you'.

(7) $\varnothing \quad$ som nya (a)de

SVCN: sonnyade 'merit'

(8) a kye nya de

+ NOM divide obtain thing

SVCN: akyenyade 'share'

(9) a kasa bo din

+NOM speak mention name

SVCN: akasabodin 'repeated mentioning of a matter with indignation or cursing' 


\section{(10) a hye ye de(c) \\ + NOM fix do thing \\ SVCN: ahyeyede 'duty/obligation'}

Thus we see NP complements such as ade(c) 'thing' and din 'name' occurring in the SVCN as these elements have become part of the SVC/SVCN due to lexicalization. Lexicalization can be understood as the extent to which formerly disparate lexemes come together to be regarded as a single unit. Typically this is in the form of relator nominals although we have shown examples of NP and PP complements which are incorporated in the SVC and SVCN above. We find, however, where lexicalization does not exist between the verbal elements and other elements, nominalization will take place to the exclusion of these elements. Consider the following examples:

$$
\begin{aligned}
& \text { Me-gye Kofi di } \\
& \text { 1SG-receive Kofi eat } \\
& \text { 'I believe Kofi.' } \\
& \text { SVCN: gyedi (*[NP]gyedi) 'belief' }{ }^{1}
\end{aligned}
$$

The example in (11) shows that in the FL-ISVC there are placeholders in the schema which are filled by random internal arguments. However, given that nominalization of FL-ISVCs is largely dependent on the degree of lexicalization, we do not typically see just any internal argument that happens to occur in the sentence becoming a part of the nominal. ${ }^{2}$ These examples show that single lexical verbs can be made into nouns; therefore, the degree to which a lexical verb can be made into a noun in the language should give a predictive indication of the degree to which a lexicalized verb can be made into a noun in that it functions, in many respects, as a single lexeme. Thus, nominalization does not include just any random internal argument that happens to appear in the SVC. Typically there has to be a conceptual semantic integration in the minds of speakers that links the formerly disparate parts making them conceptually one. This is the case in gye...di in that the SVC means something different from what is meant by either verb alone. However, there is no lexicalization that makes Kofi (in 11) a part of the single lexeme and indeed Kofi could be replaced by any NP. This is not the case for either gye or $d i$ as both are part of the high restriction on collocability. Indeed, most prototypical FL-ISVCs will show a high degree of restricted collocability and will be resistant to replacement of internal components. This means that antonyms and/or synonyms cannot be switched in and out for either verb as shown in (19a-c).

\footnotetext{
${ }^{1}$ It is important to note that examples like the following are not serial verb constructions in that they involve one verb te (so 'top' is not a verb but a relator noun and as such, this example is irrelevant to the discussion at hand).

M-a-te wo so

1SG-COMPL-pluck 2SG top

'I have reduced the price for you'

SVCN: ntesoo (*[NP]ntesoo) 'reduction'

${ }^{2}$ Note, however, CCSCs which freeze the entire sentence include various types of linguistic elements.
} 


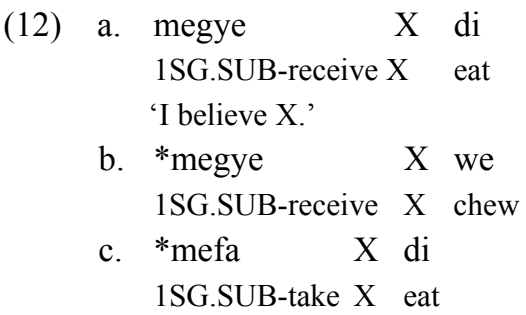

When V1 and V2 slots are unavailable for the insertion of alternative elements, this is due to restrictions on collocability. As such, introducing other verbs, regardless of semantic similarity, blocks the idiomatic meaning from being realized (Kambon 2012). While it is true that in the language the $\mathrm{X}$ position can be filled by a complement, that random complement is not subject to the lexicalization effects that link V1 and V2 together along with non-verbal elements which are part of the semantically integrated lexicalized form. It is true, however, that the relator nouns ${ }^{3}$ combine with the verbs to give idiomatic meanings and, when they do, they are a part of the lexicalized complex. This phenomenon of idioms being a lexicalized combination of lexemes of various linguistic categories is not unique to Akan, but is well-attested cross-linguistically. It should further be noted that idiomatic meanings are not incorporated in general rules about constructions, especially when the said rules are meant to be typological. Nor are elements that are not part of the lexicalized idiomatic construction expected to be carried over into the nominal form. While CCSCs are a separate case that will be dealt with separately below, it is extremely important that the features of Fully-Integrated SVCs be thoroughly explored as these are the most productive SVCs in Akan with regard to nominalization with over $98 \%$ of them being subject to nominalization. PL-ISVCs are far more common in the language, but less than $3 \%$ of them can be nominalized (Kambon 2012). Therefore, any discussion of SVC nominalization in Akan should logically focus first and foremost upon the FL-ISVC. The conclusions drawn with regard to this most productive type of SVC nominal may contribute uniquely to the definition of the SVC as a cross-linguistic phenomenon, especially where semantic integration and lexicalization (including verbal and non-verbal elements) are the predominant variables at play where nominalization is concerned.

While this paper is not the first to mention nominalization in connection with SVCs, earlier researchers have used it as a test for verb serialization. What differentiates this study from previous works is that, here we are looking at the significance of non-verbal elements that are part of the lexicalization process discussed above in the accomplishment of two specific related tasks: nominalization and decomposition of nominal.

Relevant to these tasks, the current study follows a typology of SVCs in Akan on the basis of semantic integration and lexicalization influenced by a prototype theory (PT) framework. Following this typology, there are three types of serial verbs in Akan; namely Full LexicalizedIntegrated Serial Verb Constructions (FL-ISVCs), Partial Lexicalized-Integrated Serial Verb Constructions (PL-ISVCs) and Clause Chaining Serial Constructions (CCSCs), a typology from

\footnotetext{
${ }^{3}$ In this paper we adopt the approach argued by Osam et al (2011) who introduce the term "relator noun" as "The term relational/relator noun $(\mathrm{RN})$ has been used to refer to words, nominal in origin, which express spatio-temporal and locative concepts." They further argue that "evidence from Akan shows that the socalled postpositions are not only derived from but behave syntactically as nouns and are better analyzed as relational/relator nouns."
} 
Osam 1994. "Ranking high on the scale of integration are those verbal combinations that have become fully lexicalized into verb compounds and which are used as lexicalized idioms" (1994:238).

Examples of FL-ISVCs and their nominalized forms are below. Note that for each example (a) gives the Serial Verb Construction illustrating the verb form while (b) gives the nominalized form.
a. O-twa-a
ascm no
to-o
no
so.
3SG-cut-COMPL issue DET throw-COMPL 3SG.OBJ on
'He/she falsely accused him/her.'
b. N twa to so (o)
$+\mathrm{NOM}$ cut throw on $+\mathrm{NOM}$

SVCN: ntwatoso(ว) 'false accusation'

(14) a. O-a-to burodua no a-twene.

3SG-PERF-throw corn cob DET PERF-fling

'He/she has thrown the corncob away.'

b. $(0 / \varnothing)$ to twene

+NOM throw fling

SVCN: totwene 'desertion, abandonment'

(15) a. Me-te ma no.

1SG-feel give him/her

'I feel for him/her' (I have sympathy for him/her.)

b. (o/ø) t(s)e ma

+ NOM feel give

SVCN: (ग)tema 'sympathy, empathy'

(16) a. Fa nsuo no to nsa no ho.

Take water DET put liquor DET body

'Compare the water to the liquor.'

b. N fa to ho

+NOM take throw body

SVCN: mfatoho 'comparison, example'

As we can see, some FL-ISVCs such as (1) and (4) include not only the verbs, but also relator nouns, such as so 'on' and ho 'body'. These types of FL-ISVCs with non-verbal elements form just over $20 \%$ of 164 FL-ISVCs identified in the language as we will discuss further below.

Osam (1994) describes the second type of serial verb construction, the PL-ISVC, as:
cases where speakers productively put certain verbs together to express unitary concepts ... Being less integrated implies that the verb combination is not highly lexicalized. In a way, in these verb combinations, we can almost see the separate parts of the event. For example, if we take tow ... bo 'throw at' we can see the act of 'throwing' and that of 'hitting'. [206]

Below, we can see instances of the PL-ISVCs, which, while the most productive type of SVC in Akan, have the least nominalized forms proportionally out of the three types outlined above. 
(17)
a. M-a-didi a-mee
1SG.SUBJ-PERF-eat PERF-be full
'I have eaten and become full.'

b. $ø / \mathrm{a} / \mathrm{e}$ didi mee

$+\mathrm{NOM}$ eat to be full

SVCN: (a)didimee 'the act of eating and becoming full'

(18) a. J-be-foro bepo no a-siane

3SG.SUBJ-FUT-climb mountain DET FUT-descend

'He/she will climb and descend the mountain.'

b. a foro $\operatorname{sian}(\mathrm{e})$

+ NOM climb descend

SVCN: aforosian(e) 'ascending and descending'

(19) a. Ye-a-kye no a-ton

1PL-PERF-catch 3SG.OBJ PERF-sell

'We have captured and sold him/her.'

b. a kye ton

+ NOM catch sell

SVCN: akyeton 'catching and selling'

(20) a. D-so ware

3SG.SUBJ-big long

'He/she is big and tall.'

b. o so ware

+ NOM big tall

SVCN: ssoware 'a big and tall person'

A major difference between the first and second types of serial verbs outlined above is that FLISVCs are non-compositional and idiomatic while PL-ISVCs are wholly compositional and pattern more like collocations (Kambon 2012).

In Clause Chaining Serial Constructions (CCSCs), the third type of serial verbs, "the number of VPs in the sequence has no upward bound, each verb has its full independent meaning, and linear sequence reflects temporal sequence, each VP expressing an event distinct from its successor" (Hellan, Beermann et al.:1). Examples of CCSCs and their nominalized forms are as follows:

(21) a bisa nsu a ma nsa $+\mathrm{NOM}$ ask water +NOM give liquor

SVCN: abisa-nsu-ama-nsa 'liberal, generous, bountiful, munificent' (Christaller 1933:23)

(22) a di a boro wo kora + NOM eat + NOM beat 2SG.POSS calabash

SVCN: adi-aboro-wo-kora 'fungi' (Christaller 1933) 
$\begin{array}{llllll}\text { (23) } & \varnothing \quad \mathrm{p} \varepsilon & \text { wo } & \text { a } & \text { ye den } \\ \text { +NOM look for } & \text { you } & \text { PERF } & \text { do } & \text { what }\end{array}$

SVCN: pewoayeden 'why should (I) look for you?' (Obeng 2001:100)

(24) 0 woro kawa fa batire

$+\mathrm{NOM}$ remove ring pass shoulder

SVCN: o-wors-kawa-fa-batire 'one who does the impossible' (Obeng 2001:75)

Kambon (2012) argues that distinct nominalization behavior provides independent evidence of this typology along the lines of semantic integration and lexicalization.

In this paper, we turn our attention to FL-ISVC nominalization exclusively, as this is the type of nominalization with the most robust and relevant data to the task at hand: determining the

significance of non-verbal elements in SVCs by means of nominalization tests and decomposition tests. Our hypothesis is that the significance of non-verbal elements is due to semantic integration wherein non-verbal elements are semantically integrated and form an obligatory part of the lexicalized SVC. Because the non-verbal elements are obligatory, we anticipate that, when left out, speakers will be unable to nominalize the verbs alone. Secondly, we anticipate that when decomposing SVC Nominals, speakers will tend to include non-verbal elements when breaking down the SVC rather than privileging verbal elements, as tends to be done in some SVC definitions. Finally, we anticipate that, also due to semantic integration, that when giving the meanings of the constituent parts of a decomposed nominal, speakers will tend toward giving gestalt meanings rather than separate meanings ascribed to individual verbs when they occur outside of the SVC context.

We will give a brief introduction detailing the background of the study and how it was undertaken. We will then discuss the methodology used for native speaker production of nominals from SVCs provided and for the decomposition of SVCNs to their constituent elements. We will finally bring in our findings and discussion of native speaker judgments of decomposition and composition of SVCNs with our conclusions immediately following.

1.1 Background. This paper analyzes SVCNs, how they are composed and decomposed in Akan, and the implications of this information for extant and future definitions of SVCs in the literature. To this end, we provide a brief look at the phenomena of semantic integration and lexicalization of Full Lexicalized SVCN in Akan. For our purposes, composition refers to the combination of constituent parts to form SVCNs. Decomposition refers to the breaking up of SVCNs into their constituents. Compositionality refers to the degree to which the meaning of an utterance can be understood based on the meanings of its constituent parts. We discuss verbal and non-verbal elements in FL-ISVC nominalization. This discussion of non-verbal elements was itself part of a larger typological study which showed that nominalization behavior varied in Akan on the basis of degrees of semantic integration and lexicalization (Kambon 2012). In the broader study, a subpattern emerged wherein non-verbal elements seemed to obligatorily play a role in the nominalization task. Thus, we set out to learn how native speakers compose serial verb construction nominals (SVCNs) when given all vs. only some of the constituent elements.

As alluded to above, SVCs that, in typical syntactic constructions include non-verbal elements, were in some cases provided without such elements to see whether or not native speakers could compose the full lexicalized-SVCN from what they were given. Examples include 
fa...to...ho 'compare', twa ...to...so(J) 'falsely accuse' and ka ...bom 'unite', each of which will be discussed below. In other words, native speakers were being challenged to come up with the missing elements themselves. In other instances, we provided speakers with the nominalized form (specifically those including non-verbal elements) ahead of time and asked them to give us the serial verbs from which the SVCN is derived. The results were systematic and provided a statistically significant view into the major role played by semantic integration in highly lexicalized SVCs.

To briefly touch on what is meant by semantic integration, we turn our attention to Osam (1994). Osam shows Integrated Serial Verb Constructions (ISVCs) as originally coding separate events but "these events, through the process of cognitivization, come to be integrated as a single event" (Osam 1994:193). This cognitivization process is one of semantic integration which is, in turn, reflected in the structural integration (and subsequent lexicalization) of ISVCs. This concept of semantic integration finds its genesis in the notion of event integration (Givón 1993; 2001a; 2001b).

According to Osam (1994), the SVC types with the highest level of semantic integration have become lexicalized in that they now function semantically as a single lexical unit. This phenomenon was observed as early as Balmer and Grant (1929):

\begin{abstract}
... the concept of believing something cannot really be broken into parts, even though it is possible to argue that such combinations must have started as distinct verbs expressing distinct events which, over the course of the development of the language, have come to express purely abstract unitary concepts. So even though metaphorically a concept like 'believe' in the Akan context can be broken into parts, now speakers do not perceive such concepts as involving distinct events (p. 115).
\end{abstract}

This former compositionality must have been the original motivation behind the verb combinations as exemplified in Akan, gye ... $d i^{4}$ 'believe'. According to Balmer and Grant (1929):

The use of such verb combinations is due partly (a) to the tendency of the language to use vivid figurative expressions and partly (b) to the habit of analyzing an action into its component parts. An example of the former is in the verb ... gye ... dzi, which, literally, means to accept and eat. It embodies the thought that, when a thing is accepted and eaten, trust and confidence is implied (p. 115). (Italics ours)

Such lexicalized verb compounds in Akan, although thought to be once typically compositional, have come to be conceptualized as a single event in the language synchronically as in the case of 'believe'. Thus, in ISVCs, particularly in the case of the Full Lexicalized type, the meaning is no longer compositional synchronically, although in many cases, the etymology of the constituent parts remains transparent to varying degrees. These FL-SVCs are analogous to idioms - which share traits of being semantically integrated and lexicalized - in the sense that they are now noncompositional and meaning cannot be determined by their constituent parts. Also, like idioms they appear to require all parts to be understood and intelligible.

In this paper, we will focus specifically on FL-ISVCs with non-verbal elements, the degree to which they can be composed into SVCNs when non-verbal elements are given or withheld and how SVCNs are decomposed into SVCs. SVC types with the highest levels of semantic

\footnotetext{
${ }^{4}$ Balmer and Grant (1929) use gye...dzi, as in Fante. In the current study we use gye...di, which is found in Asante and Akuapem Twi unless otherwise noted.
} 
integration have become lexicalized to the point that they function as a single lexical unit. We posit that this lexicalization process may be the underlying cause of native speaker judgments with regard to composition and decomposition of SVCNs in the language. In the following section we will discuss the methodology used to obtain these judgments in the study.

\section{Methodology}

This section details the methodology used to determine how SVCNs are composed and decomposed in the language by native speakers and the role of non-verbal elements in that process. Native speakers of each of the three major literary dialects of Akan - Asante Twi, Fante and Akuapem Twi - were consulted through two phases of fieldwork. A number of examples of FL-ISVCs were identified from within four of the most exhaustive corpuses available in Akan which also span almost 80 years of the development of the language((Christaller 1933), (Education Department of Ghana 1971), Boadi (2005) and Bannerman et al. (2011). These corpora were selected on the basis of their comprehensiveness and the diversity of time periods in which they were produced. They were also selected due to representation of the three major literary dialects of Akan.

Once FL-ISVCs were identified from the corpora, they were presented to native speakers in the fieldwork component in which written and oral questionnaires were utilized. For the questionnaire phase, participants were selected using purposeful sampling (Patton 2002:230). Participants were selected on the basis of various criteria collected as biographical data with a primary focus on dialect of Akan spoken, education/literacy, and age. For Phase One (P1) questionnaires were distributed primarily at Winneba (University of Education-Winneba) 17.9\%, Accra (University of Ghana- Legon) 48.1\% and Cape Coast (University of Cape Coast) 37.3\%. Questionnaires for P1 were distributed among linguistics students and Akan language students due to the fact that the composition and decomposition tests required some level of sophistication in sentence analysis and a formal understanding of the language.

Data collection occurred in two phases; Phase One (P1) and Phase Two (P2) involving one hundred (100) participants. P1 Akan FL-ISVC data are based on seventy-five (75) questionnaires. P1 focused primarily, though not exclusively, on literate youth between the ages of 21-40 with 63 out of the 75 falling within this range. In terms of biographical data, we collected information on gender, age, occupation, education, location, native language, and other languages spoken. The rationale for selection on the basis of these factors were inclusivity (major literary dialects), broadness of educational backgrounds (no formal education to higher education) and for diachronic/synchronic representativeness (age). Purposeful sampling allowed us to select information-rich cases for in-depth study; basing the selection on the aforementioned criteria was an intentional effort to militate against bias and narrowness in the study.

For P2, the total number of participants was twenty-five (25). In P2 fieldwork, the focus was primarily on older speakers, the majority of whom were non-literate, representing speakers of Fante, Akuapem Twi and Asante Twi. Twenty-two of the participants were over 60, two were in the range 50-60, and one was in the range 40-50.

P1 was conducted via questionnaire, taking advantage of the fact that all of the participants were literate Akan language and linguistics students and teachers. This population was chosen because only they would know what serial verbs are. Steps were taken to insure that participants possessed the required knowledge to answer questions with regard to Akan sentence structure and 
word classes. As linguistics specialists and native speakers, they were expected to be familiar with word categories. Due to the nature of the questionnaire, we found that typically those who had problems with the task recused themselves by leaving the questionnaire uncompleted. This led us to exclude participant who answered less than $50 \%$ of the questionnaire.

In the composition task, speakers were given examples with and without the relator noun such as $f a$...to...ho vs. $f a$...to, to see whether the participant could "recover" the relator noun when it was excluded. It should be noted that prompting with examples including the relator noun and excluding the relator noun was necessary for the purpose of determining how significant the relator noun is in the composition test. If, for example, the non-verbal element was not a critical part of the equation, it would be expected that its exclusion would be irrelevant to completing the nominalization task. However, as will be shown below, participants were typically able to create the noun only when all elements were included. Significantly, this was the case despite having been previously "prompted" with the full SVC elements $f a$...to...ho. This insight shows that being prompted with a form did not seem to have any impact on subsequent tasks in the questionnaire. In fact, $90.3 \%$ of respondents were able to produce the form mfatoho 'comparison/example' when initially given each element $f a$ 'take', to 'throw/put/place/lay' and ho 'beside', while only $7.4 \%$ were able to produce the form when only given $f a$...to. The majority said that there is no noun that can be produced from $f a$...to even after having just provided $m f a t o h o$ ! The verbs alone did not trigger the expected response. If being given a form influenced subsequent answers, it would be expected that $90.3 \%$ of respondents would have looked at the $f a$...to...ho/mfatoho set they produced earlier and produced mfatoho. Thus, although it could be seen as a methodological weakness that respondents were given the relator noun form, this was necessary due to the need to see whether or not the relator noun influenced the nominalization task. The example above, however, demonstrates clearly that respondents were not demonstrably influenced by information provided in one part of the questionnaire in carrying out the tasks required of them in another part of the questionnaire.

P2 was undertaken 1) so that P1 would not be seen as a "convenience sample" focusing only on young literate linguistics specialists and 2) to ascertain the views of elderly, non-literate speakers. Because fifty-six percent of the P2 participants were non-literate, a different approach had to be employed to account for the mixture of non-literate, semi-literate and literate. As such, focus groups were convened 'on-location', where questions on nominalization were presented orally and recorded on the spot. Specific instructions were given where participants were prompted with an example sentence including an SVC such as:

$\begin{array}{llllll}\text { Fa nsuo no to nsa no ho. } & \text { n } \\ \text { Take water } & \text { DET throw liquor } & \text { DET body } \\ \text { 'Compare the water to the liquor.' }\end{array}$

The participants were given some examples of SVCs and their corresponding nominalizations. After this correlation and what they were expected to do was fully understood, responses of SVCNs flowed freely upon giving SVC sentences as prompts to the point that no further instruction was required. The stimulus SVC alone elicited the desired type of responses. 


\section{Findings and Discussion}

3.1 Composition and Decomposition of SVCNs. We present below a few of the many lexicalized SVCs that include non-verbal elements. Respondents in the study were given SVCN forms such as mfatoho 'example, comparison' and were asked to decompose the form into its constituent verbs $f a$ 'take' and to 'put, place' and to give the meaning of each verb. Respondents would consistently give not just the verbal elements but would also include relator nouns whenever they were present in the SVCN structure. Even in cases where the respondent gave only the verbal elements, oftentimes they gave the relator noun as well and then crossed it out or put it in parentheses upon realizing that they were asked to give only the verbs. For each SVCN that included a relator noun, such as the example mfatoho 'example, comparison' mentioned above, a majority of respondents typically included the verbal elements and the relator nouns, postpositions or demonstratives in nearly all cases (i.e. $f a$ 'take' to 'put/place' ho 'around, beside'). We analyze this phenomenon as evidence of how native speakers truly see these inherently collocational and idiomatic SVCNs and the underlying FL-ISVCs from which they are derived.

This is most clearly exemplified in $f a . . . t o . . . h o$ versus $f a . . . t o$ nominalization. In the case of mfatoho, the nominalizing element is $\mathrm{N}+\mathrm{NOM}$, as below:

(26) a. Fa nsuo no to nsa no ho.
Take water DET throw liquor DET body
'Compare the water to the liquor.'
b. $\mathrm{N}$ fa to ho
+NOM take throw/put/place/lay body
SVCN: mfatoho 'comparison, example'

We found that $90.3 \%$ of respondents were able to produce the form mfatoho 'comparison, example' when given each element $f a$ 'take', to 'throw/put/place/lay' and ho 'beside' while only $7.4 \%$ were able to come up with the same mfatoho form when only given the verbal elements $f a$ and to without the relator noun ho.

In terms of lexical decomposition, when given the SVCN form mfatoho, 83.1 percent of P1 respondents gave $f a$ to ho which, of course, included the relator noun ho as part of the SVC complex. In contrast only $6.2 \%$ gave solely the verbal elements $f a . . . t o$.

As an FL-ISVC, fa...to...ho fits most of the prototypical characteristics expected in relation to compositionality, collocability and familiarity expected of an idiomatic form. Furthermore, for the SVCN, mfatoho 'comparison/example' it is interesting to note here that $f a$ is glossed as 'take', yet the majority of $\mathrm{P} 1$ respondents gave the composite meaning of the entire FL-ISVC 'compare'. Although respondents were asked to give only the meaning of the separate individual verbs from which mfatoho is derived, they regularly gave the composite meaning. All of these considerations speak to the reality of semantic integration of the elements in the SVC/SVCN for speakers of Akan.

The next FL-ISVCN is nkabom(u) 'unity'. 

a. Ye-a-ka
yen
ho a-bom
1PL.SUBJ-PERF-touch
1PL.POSS
body
PERF-together
'We have united.'
b. $\mathrm{N}$ ka bo $\mathrm{m}(\mathrm{u})$
+ NOM touch strike inside
SVCN: nkabom(u) 'unity'

$K a \ldots b$...mu was also an item on the questionnaire distributed to participants. ${ }^{5}$ Here we see clear evidence of $n k a b o m(u)$ as a highly familiar form in that $95.8 \%$ of P1 respondents were able to produce the SVCN form nkabom $(u)$ when given the FL-ISVC elements $k a \ldots b s . . . m u$. $100 \%$ of P2 respondents were able to produce the same form making this the most familiar form interdialectally, not only conceptually, but formally. There was also consensus on the general meaning of $n k a b o m(u)$ as respondents gave synonyms or closely related glosses of the SVCN as 'unity' such as 'togetherness'.

When given the SVCN nkabom $(u), 95.5 \%$ of all P1 respondents were able to ascertain that the FL-ISVC from which it is derived is $k a . . . b o . . . m u$ or $k a . . . b o m$ in accounting for cliticization of the postposition $m u$ 'inside' (2011). It is also significant that no respondents ( $0 \%$ ) gave $k a$...bo as the verbs from which nkabom $(u)$ 'unity' is derived. This is seen as lexicalization/semantic integration extended to the postposition, $m u$ 'inside'.

In giving the meaning of $k a$ in $n k a b o m(u), 35.2 \%$ of $\mathrm{P} 1$ respondents gave the meaning of 'add up/gather', again a composite meaning of nkabom(u) rather than what the individual verbs would mean by themselves outside of the context of an FL-ISVCN.

Ntwatoso(o) 'false accusation' was also presented to speakers in the study. Given the FL-ISVC elements $t w a \ldots t o . . . s o$, an overwhelming majority of $\mathrm{P} 1$ respondents, $97.2 \%$, gave the expected form of ntwatoso(ว).
a. O-twa-a asem no to-o no so.
3SG-cut-COMPL issue DEF throw-COMPL 3SG.OBJ on
$\mathrm{He} /$ she falsely accused him/her.
b. $\mathrm{N}$ twa to so (o)
$+\mathrm{NOM}$ cut throw on $+\mathrm{NOM}$
SVCN: ntwatoso(5) 'false accusation'

When given the SVCN, ntwatoso(3) 'false accusation', 87\% of P1 respondents gave all three elements of the FL-ISVC including the relator noun while only $6.2 \%$ gave just $t w a \ldots t o$. This demonstrates that for native speakers, the relator noun is just as much a part of the construction as the verbal elements.

Although $t w a$ 'cut' as a verb is relatively unambiguous, with $55.3 \%$ of P1 respondents giving its definition as 'cut', $27.7 \%$ gave the composite definition of twa...to...so 'to accuse falsely' as an FL-ISVC unit. This goes to the point of semantic integration in that the pattern amongst speakers has been that, for many, the meanings of the individual verbs are secondary to the composite meaning even when asked to give the meaning of the individual verbs and the meaning of those verbs is unambiguous.

The next SVCN to be discussed is mmotohs 'procrastination'.

\footnotetext{
${ }^{5}$ See appendix A for a sample questionnaire that was used in the study.
} 

a. O-a-bo
adwuma no
a-to
ho.
3SG-PERF-strike work
DEF PERF-throw
DEM

'He/she put the work aside.'

b. $\mathrm{N}$ bo to ho

+ NOM strike throw there

SVCN: mmstohs 'procrastination'

Included in the nominalized form is the demonstrative, $h$ ' 'there'. Agreement was found with P1 respondents who, when given the FL-ISVC elements bo to ho, $82.9 \%$ reported the SVCN form mmotoho/mbstohs ${ }^{6}$. Also, $86 \%$ of respondents came up with procrastination/postponement as the meaning of mmotoho as also attested in written sources. Respondents were also readily able to identify the verbs from which mmotoho is derived with a combined $75.8 \%$ identifying bo to ho but only $4.5 \%$ bo to as the verbs from which the SVCN is derived. Also, when asked to give the meanings of the verbs from which mmotoho is derived, a statistically significant $29.5 \%$ of respondents gave the gestalt meaning of 'procrastination' rather than the meanings of the individual verbs $b s$ 'strike' and to 'throw/place/put/lay'.

It should be emphasized, however, that while these are some of the more salient and compelling examples, these are not the only instances of non-verbal elements in FL-ISVCs in Akan that show this type of behavior. Further examples are listed in Table 1:

Table 1: FL-ISVCs with Non-Verbal Elements

\begin{tabular}{|c|c|c|c|c|c|c|c|}
\hline \# & A & V1 & DO & $\mathrm{V} 2$ & RN/PP & SVCN & Gloss \\
\hline 1. & $\mathrm{~N}$ & bo 'strike' & & to 'throw' & ho 'there' & mmotoho & 'procrastination' \\
\hline 2. & $\mathrm{~N}$ & bo 'strike' & & to 'throw' & so 'on' & mmotoso & 'false accusation' \\
\hline 3. & $\varnothing$ & bu 'calculate' & & $\begin{array}{l}\text { tra 'jump, } \\
\text { cross' }\end{array}$ & so 'top' & butraso & 'overestimation' \\
\hline 4. & $\mathrm{~N}$ & fa 'take' & & to 'throw' & ho 'body' & mfatoho & 'comparison' \\
\hline 5. & $\mathrm{~N}$ & fa 'take' & & ka 'touch' & ho 'body' & mfakaho & 'addition' \\
\hline 6. & $\mathrm{~N}$ & fem 'loan' & & to 'throw' & mu 'inside' & mfentom & 'interest' \\
\hline 7. & $\mathrm{~N}$ & gye 'receive' & & to 'throw' & mu 'inside' & nnyetomu & 'agreement' \\
\hline 8. & $\mathrm{~N}$ & hwe 'strike' & & bo 'strike' & mu 'inside' & nhwebom & 'cooperation' \\
\hline 9. & 0 & hye 'fix' & & to 'throw' & ho 'there' & ohyctoho & $\begin{array}{l}\text { 'agreement, } \\
\text { contract' }\end{array}$ \\
\hline 10. & $\mathrm{a}$ & hye 'fix' & & ye 'do’' & de 'thing' & ahycyede & 'duty, obligation' \\
\hline 11. & $\mathrm{~N}$ & ka 'touch' & & bo 'strike' & ho 'body' & nkaboho & 'annexation' \\
\hline 12. & $\mathrm{~N}$ & ka 'touch' & & bo 'strike' & mu 'inside' & nkabom(u) & 'unity' \\
\hline 13. & 0 & ka 'touch' & & gu 'spill' & so 'top' & okaguso & 'accusation' \\
\hline 14. & $\mathrm{~N}$ & ka 'touch' & & hye 'fix' & mu 'inside' & nkahyem & $\begin{array}{l}\text { 'siege, } \\
\text { confinement' }\end{array}$ \\
\hline 15. & $\mathrm{~N}$ & ka 'touch' & & ku 'join’ & ho 'body' & nkakuho & reduplication \\
\hline$\#$ & A & $\mathrm{V} 1$ & $\mathrm{DO}$ & $\mathrm{V} 2$ & $\mathrm{RN} / \mathrm{PP}$ & SVCN & Gloss \\
\hline
\end{tabular}

${ }^{6}$ Dialectal differences in spelling and pronunciation such as that between mmstohs (Asante and Akuapem Twi) and mbstohs (Fante and Akan Standard Orthography) were regarded as irrelevant. 


\begin{tabular}{|c|c|c|c|c|c|c|c|}
\hline 16. & $\mathrm{~N}$ & ka 'speak' & & $\begin{array}{l}\text { san } \\
\text { 'return' }\end{array}$ & mu 'inside' & nkasanmu & 'repetition' \\
\hline 17. & $\mathrm{~N}$ & ka 'speak' & & $\begin{array}{l}\text { sram } \\
\text { 'inundate' }\end{array}$ & so 'top' & nkasramso & 'harrowing' \\
\hline 18. & $\mathrm{~N}$ & ka 'speak' & & to 'throw' & ho 'there' & nkatoho & 'agreement' \\
\hline 19. & 0 & ka 'touch' & & to 'throw' & so 'top' & okatoso & 'accusation' \\
\hline 20. & $\mathrm{~N}$ & ka 'touch' & & $\begin{array}{l}\text { toa } \\
\text { 'connect' }\end{array}$ & mu 'inside' & nkatoam' & 'connection' \\
\hline 21. & $\mathrm{~N}$ & ka 'speak' & & twa 'cut' & mu 'inside' & nkatwam' & $\begin{array}{l}\text { 'that which is } \\
\text { unspeakable, } \\
\text { inexpressible' }\end{array}$ \\
\hline 22. & $\mathrm{a}$ & kasa 'speak' & & $\begin{array}{l}\text { bo } \\
\text { 'mention' }\end{array}$ & din 'name' & akasabodin & $\begin{array}{l}\text { 'repeated } \\
\text { mentioning of a } \\
\text { matter with } \\
\text { indignation or } \\
\text { cursing' }\end{array}$ \\
\hline 23. & 0 & kasa 'speak' & & $\begin{array}{l}\text { san } \\
\text { 'return' }\end{array}$ & mu 'inside' & okasasanmu & $\begin{array}{l}\text { 'awkward } \\
\text { repetition in } \\
\text { speaking' }\end{array}$ \\
\hline 24. & $\mathrm{a}$ & kyع 'divide' & & $\begin{array}{l}\text { nya } \\
\text { 'obtain' }\end{array}$ & ade 'thing' & akyєnyade & 'share' \\
\hline 25. & $\mathrm{~N}$ & pae 'split' & & si 'stand' & ho 'body' & mpaesiho & $\begin{array}{l}\text { 'to pay or charge } \\
50 \% \text { interest' }\end{array}$ \\
\hline 26. & 0 & percw 'shift' & & to 'throw' & so 'top' & operctoso & 'shifting of blame' \\
\hline 27. & 0 & pono 'bend' & & to 'throw' & mu 'inside' & oponontom' & 'pocketknife' \\
\hline 28. & $\mathrm{a}$ & $\begin{array}{l}\mathrm{s} \varepsilon \text { 'to be } \\
\text { proper' }\end{array}$ & & $\mathrm{y} \varepsilon$ 'do' & de 'thing' & ascyede & 'duty' \\
\hline 29. & $\varnothing$ & som 'serve' & & $\begin{array}{l}\text { nya } \\
\text { 'obtain' }\end{array}$ & ade 'thing' & sonnyade & 'merit' \\
\hline 30. & $\mathrm{~N}$ & te 'tear' & & $\begin{array}{l}\text { ka } \\
\text { 'remain' }\end{array}$ & mu 'inside' & ntekam' & 'omission' \\
\hline 31. & $\mathrm{~N}$ & $\begin{array}{l}\text { twa 'cut, } \\
\text { cross' }\end{array}$ & $\begin{array}{l}\text { ho } \\
\text { 'body' }\end{array}$ & $\begin{array}{l}\text { hyia } \\
\text { 'meet' }\end{array}$ & & ntwahohyia & 'circumference' \\
\hline 32. & $\mathrm{~N}$ & twa 'cut' & & to 'throw' & so 'on' & ntwatoso & 'false accusation' \\
\hline 33. & $\mathrm{a}$ & wu 'die' & & gya 'leave' & de 'thing' & awunnyade & 'inheritance' \\
\hline 34. & $\mathrm{~N}$ & yi 'remove' & & $\begin{array}{l}\text { fi 'from, } \\
\text { leave' }\end{array}$ & mu 'inside' & nyifim' & 'subtraction' \\
\hline 35. & $\mathrm{~N}$ & yiri 'flood' & & $\begin{array}{l}\text { sram } \\
\text { 'inundate' }\end{array}$ & so 'top' & nyirisramso & 'inundation' \\
\hline
\end{tabular}


3.2 Pattern of Composite SVC Meanings. Respondents established a pattern of providing the composite meaning rather than meanings of the individual verbs. This pattern was observed for SVCs with and without nonverbal elements. We will explore some cases of this phenomenon below.

The first is the FL-ISVC gye...di 'believe'. A surprising $95.9 \%$ of $\mathrm{P} 1$ respondents produced the SVCN with a combined meaning of 'belief' or 'faith', making it one of the most familiar formsin the study. In terms of identifying the verbs from which gyedie 'belief' is derived, $100 \%$ of respondents were able to correctly identify FL-ISVC gye...di. The only participants who did not come up with this answer were those who did not answer. Of $\mathrm{P} 2$ respondents, again, $100 \%$ of them were able to produce some nominal from with gye...di.

Respondents were also clear on the meaning of gye alone, coming up with largely synonymous meanings of 'receive' 'take/get' and 'collect'. However, consistent with the previously alluded to pattern, $45.2 \%$, of $\mathrm{P} 1$ respondents, a majority for any of the single responses for this item, gave the composite meaning of 'believe/have faith'. Again, this phenomenon is thought to be due to the effects of semantic integration and lexicalization.

The next FL-ISVC is so...hwe and is one of the most familiar forms based on attestation in corpora and on questionnaire responses.
a. So bi hwe.
spark INDEF look
'Try some of it'
b. N/o/ø so hwe
$+\mathrm{NOM}$ spark look
SVCN: nsohwe/osohwe/sohwe 'test'

The majority of P1 respondents gave one or more of three answers for the meaning of nsohwe 'test/exam'. Over fifty-five percent of respondents chose 'test' and others wrote 'exam', which we collapsed into the same answer. Twenty one percent of respondents chose another composite meaning of 'temptation' as the gloss. An additional $20.2 \%$ of respondents chose both 'test' and 'temptation' as their response. In terms of familiarity, $n s \jmath h w \varepsilon$ is seen as a highly institutionalized and current lexical item. Also, ninety-seven percent of all respondents were similarly able to come up with the same FL-ISVC from which $n s \jmath h w \varepsilon$ is derived as $s \jmath . . h w \varepsilon$.

In terms of compositionality, the majority of respondents gave 'try' $(32.7 \%)$, 'test' $(32.7 \%)$ or 'tempt' (5.5\%). This means a combined $70.9 \%$ of respondents gave a composite meaning of so...hwe when asked the individual meanings of the individual verbs so and $h w \varepsilon$. Again, this widespread pattern amongst respondents is evidence of semantic integration.
a. Ye-a-bo
asem no a-gu.
1PL.SUBJ-PERF-strike issue DEF PERF-spill
'We have rejected the idea.'
$\begin{array}{lll}\text { b. } & \mathrm{N} \text { bo gu } \\ \text { +NOM strike } & \text { pour/spill }\end{array}$
SVCN: mmoguo 'rejection/interlude' 
Mmoguo is derived from $b o$ 'strike' and $g u$ 'pour/spill'. When asked the verbs from which mmoguo is derived, amongst P1 speakers, a relative consensus was reached with a valid percent of $84.8 \%$ (56 respondents) selecting $b \ni . . . g u$. However, there was no consensus on the meanings of constituent verbs $b$ and $g u$. For $b o$, respondents gave answers such as 'hit/beat' $22.2 \%$ (10 respondents), not sure $15.6 \%$ (7 respondents), 'kick' 11.1\% (5 respondents), 'play' $11.1 \%$ (5 respondents), 'ignore' $11.1 \%$ (5 respondents), 'none' $4.4 \%$ (2 respondents) and a host of answers with $2.2 \%$ (1 respondent) such as 'break', 'condemn', 'joke' etc. For gu responses included 'away' $19.4 \%$ (6 respondents), 'pour' 19.4\% (6 respondents), 'not sure' 19.4\% (6 respondents), 'sow' $12.9 \%$ (4 respondents) and many with 3.2\% (1 respondent) such as 'nurse', 'out', 'fall', 'fail' and 'scatter'. It is important to note here that both $b$ and $g u$ have varied meanings, depending on context, with Christaller's (1933) dictionary alone providing 115 senses of the word bo and 33 senses of the word $g u$.

The varied $\mathrm{P} 1$ responses show that neither word has a meaning independent of the SVC and that the meaning of the two together is dependent on the SVC structure as a whole. For these speakers, mmoguo was ascribed to have two homophonous forms with two distinct composite meanings, 'interlude' and 'rejection', with P1 respondents split on the definition with $26.7 \%$ (12 respondents) providing the meaning as 'interlude' while $22.2 \%$ (10 respondents) gave 'rejection' as the meaning. As such, speakers, while clear on what the composite whole means, they may be unsure or, at the very least, divided on what the constituent elements mean outside of the SVCN complex. It is viewed as a testament to the high level of semantic integration, even in the case of homophones

The next FL-ISVC/SVCN combination of $f a . . . k y \varepsilon$ 'forgive' and fakye, forgiveness was also a questionnaire item. As with other FL-ISVCs, $f a \ldots k y \varepsilon$ is non-compositional.
$\begin{array}{llll}\text { a. fa } & \text { ne bone } & \text { kye no } \\ \text { take } & \text { 3SG.POSS badness } & \text { give as gift } 3 \text { SG.OBJ }\end{array}$
'I forgave him/her for his/her badness/transgression.'
b. $\varnothing \quad$ fa $\mathrm{ky \varepsilon}$
$+\mathrm{NOM}$ take give as gift
SVCN: fakye 'forgiveness'

When asked to produce the verbs from which the SVCN fakyc is derived, 89.4\% of P1 respondents were able to correctly identify $f a . . . k y \varepsilon$ as the source. When asked about the meanings of the individual verbs from which the SVCN fakyc is derived, many speakers, $40.0 \%$ of P1 respondents, chose the combined meaning of FL-ISVC $f a . . . k y \varepsilon$ 'forgive'. The majority of respondents in this case, however, at $45.5 \%$ were able to give the prototypical meaning of $f a$ 'take'. Although speakers were able to come up with the meaning of the verb $f a$ 'take', when we juxtapose this with the typically $100 \%$ of speakers who give the meaning of each in cases when there is partial lexicalization, the explanation can only be semantic integration and lexicalization. Thus, in short, in the case of $f a k y \varepsilon$, as we are dealing with a semantically integrated non-compositional FL-ISVC, composite whole meanings are typically the rule rather than the exception in native speaker judgments.

The last SVCN is oyima 'treachery, donation' which is derived from the FL-ISVC yi...ma. Oyima is non-compositional, inflexible and collocationally closed. 

a. o-a-yi me a-ma
3SG.SUBJ-PERF-remove 1SG.OBJ PERF-give
'He/she has betrayed me.'
b. o/ø yi ma
$+\mathrm{NOM}$ remove give
SVCN: (o)yima 'treachery, donation'

\begin{abstract}
Ninety-seven percent of P1 respondents were able to correctly identify the FL-ISVC from which oyima is derived as yi...ma. In giving the meaning of the individual verbs from which the SVCN oyima is derived, $31.8 \%$ of $\mathrm{P} 1$ respondents gave the gloss of $y i$, as 'take' while $29.5 \%$ glossed it as 'remove'. Both are relatively prototypical meanings of $y i$ when taken alone. However, consistent with the pattern of respondents with all familiar FL-ISVCs covered in the study, a statistically significant $27.3 \%$ of $\mathrm{P} 1$ respondents gave the composite meaning of 'betray' for $y i$ with an additional $2.3 \%$ giving the composite meaning of 'give'. Eighty-three of P1 respondents glossed $m a$, which is relatively unambiguous, as 'give'.
\end{abstract}

\title{
4. Conclusions
}

This paper focuses on the nominalization of Serial Verb Constructions (SVCs) in Akan. In this study, we found evidence of semantic integration including both verbal and non-verbal elements in applied tests of composition (i.e. creation of SVCNs) and decomposition (i.e. decomposing SVCNs to their constituent parts) Speakers were asked to decompose the SVCN into the verbs from which a Full Lexicalized-Integrated Serial Verb Construction Nominal (FL-ISVCN) is composed. In each case, the vast majority of speakers gave the verbs as well as other obligatory constituents such as direct objects, relator nouns and postpositions. The reverse was also true in that when given only the verbs, speakers found it difficult or impossible to come up with the SVCN; but when given the other non-verbal elements, the majority were able to come up with the FL-ISVCN relatively easily. Also, when asked to give the meanings of the individual verbs from which the FL-ISVCN is derived, speakers regularly gave a composite meaning of the whole rather than the typically transparent meanings of the constituent parts. The implication is that semantic integration extends to all elements of the SVC rather than just the verbs. This observation has import for definitions of SVCs in the literature which, by and large, tend to focus on serial verbs and the relationship between them to the detriment of other demonstrably obligatory elements of the construction as a whole.

Our original hypothesis was that serial verbs of different levels of semantic integration and lexicalization could form the basis of SVCN typology in Akan. Based on theanalysis of questionnaire data, it is clear that semantic integration extends beyond the verbal elements of the SVC to demonstratives, direct objects and relator nouns when they occur as parts of the SVC. Thus, a significant finding was that relator nouns, postpositions, demonstratives and direct objects are semantically integrated parts of the SVCN.

In serial verb literature, there is typically little mention of other elements in the construction and especially nothing on semantic integration. In cases where other elements in the SVC are discussed, this is typically done in the context of argument sharing without any allusion to semantic integration of the verbal elements or the degree to which such semantic integration may extend to other such elements. Examples of argument-sharing as a defining characteristic of SVCs 
can be found in Baker's (1989) Argument Sharing Hypothesis. In other works where semantic integration between verbs is discussed in the context of nominalization (Osam 1994:205), there is no mention of this semantic integration being extended to other elements of the SVC or of how semantic integration including RNs, for example, impacts upon nominalization. Nor is there mention of how nominalization may shed light on semantic integration of all elements within the SVC from which the SVCN has been derived. Furthermore, there has been no systematic study of the cognitive basis of semantic integration by having native speakers decompose the SVCN. In this study, a clear pattern emerged when we look at other SVCNs wherein respondents included non-verbal elements when decomposing SVCNs and required nonverbal elements when composing SVCNs. The implication of the data is that, for native speakers, lexicalization and semantic integration extend not only to verbal elements in SVCs but to other elements which are a part of the FL-ISVC. This phenomenon is similar to that of idioms and collocations which require all elements of the idiomatic form/usage to be understood and intelligible. The further implication is that SVC definitions should deal not just with verbs to the exclusion of other obligatory elements, as reflecting in the following quotations by Aikhenvald (2006) and Durie (1997), respectively:

A serial verb construction (SVC) is a sequence of verbs which act together as a single predicate, with no overt marker of coordination, subordination, or syntactic dependency of any other sort (p. 1).

The archetypal serial verb construction consists of a sequence of two or more verbs which in various (rather strong) senses, together act like a single verb (pp. 289-290).

This is not to say that we have never come across definitions of serial verbs in which non-verbal elements are mentioned. Indeed, one of the earliest observations comes from Christaller (1875) in his description of "Accidental Combinations" and "Essential Combinations". He explains the two types quoted in full as follows:

Accidental combinations. Two or more predicates (verbs with or without, complements or adjuncts), expressing different successive actions, or a state simultaneous with another state or action, but having the same subject, are merely joined together without conjunction and without repeating the subject. In this case two (or more) sentences are thrown or contracted into one, and the verbs are co-ordinate in sense as well as form.

Essential combinations. One verb is the principal, and another is an auxiliary verb supplying, as it were, an adverb of time or manner. .. or forming or introducing a complement ... or adjunct ... or the second verb is supplemental, forming part of a verbal phrase ... The actions expressed by both verbs are simultaneous and in an internal or inseparable relation or connection. In this case, the auxiliary or supplemental verb is coordinate only in form, but subordinate in sense, whether it be preceding or succeeding the principal verb (p. 144).

Just shy of a century later, Schachter also gives attention to the complements of verbs within SVCs: "A sentence that contains a serial verb construction consists, on the surface at least, of a subject noun phrase followed by a series of two or more verb phrases, each containing a finite verb plus, possibly the complement(s) of that verb" (Schachter 1974:254). 
By this point, it should be eminently clear as to why we would prefer definitions such as those wherein non-verbal elements are mentioned over those which neglect them. When native speakers decompose SVCNs, they do not stop at "two or more verbs" acting as a single verb with or without syntactic dependency, but rather they identify all of the semantically integrated elements of the SVC. Thus, while prominent definitions in the literature tend to focus on 'Serial Verb' deemphasizing 'Construction', doing so may be untenable if we are looking to truly capture what native speakers know about their language. In retrospect, and as a result of the data obtained, it is more appropriate to ask speakers to decompose SVCN into all elements and discard the verbcentric assumptions found in some theoretical definitions. This is because, while not all SVCs have non-verbal elements, for those that do, the non-verbal elements are just as semantically integrated and therefore crucial in the accomplishment of the nominalization task as the verbal elements. Thus, in short, any definition of SVC which is verb-centric to the exclusion of the RNs and other such elements in the SVC is untenable in the case of Akan Serial Verb Construction Nominalization. 


\section{Appendix A}

\section{SAMPLE QUESTIONNAIRE}

This questionnaire is for the purposes of academic research into language. Answers provided will be held in strict confidence.

This questionnaire is to establish categorization of serial verbs. This questionnaire (1) asks you to provide corresponding noun forms for serial verb forms and (2) secondly you are asked to provide verb forms for nouns along with English translations. Finally (3) you are asked to judge correctness of noun forms.

1. Gender: Male. Female.

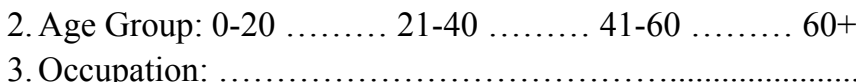

4. Highest Academic Qualification: JHS Bachelors.

Masters Doctorate SS Other (Please Specify)

5. Place/Institution:

6. Are you a native speaker of Akan? (Please specify dialect(s)) Twi Fante

Akuapem. . Other (Please specify):

7. If you are not a native speaker, what is your native language?

8. Do you speak other languages? If so please list them

A. Please make a noun out of the following serial verbs. Also give the meaning of the noun. If there is no corresponding noun form, please write NONE. If you are not sure, please write NOT SURE.

\begin{tabular}{|c|c|c|}
\hline VERB FORMS & CORRESPONDING NOUN FORM & MEANING OF NOUN \\
\hline \multicolumn{3}{|l|}{ yi ma } \\
\hline \multicolumn{3}{|l|}{ gye di } \\
\hline \multicolumn{3}{|l|}{ ko gu } \\
\hline \multicolumn{3}{|l|}{ su fre } \\
\hline \multicolumn{3}{|l|}{ bo to so } \\
\hline \multicolumn{3}{|l|}{ fa kye } \\
\hline \multicolumn{3}{|l|}{ bo gu } \\
\hline \multicolumn{3}{|l|}{ ka gu } \\
\hline \multicolumn{3}{|l|}{ gye to $\mathrm{mu}$} \\
\hline \multicolumn{3}{|l|}{ bo to ho } \\
\hline \multicolumn{3}{|l|}{ twa to so } \\
\hline \multicolumn{3}{|l|}{ so hwe } \\
\hline \multicolumn{3}{|l|}{ ka kyere } \\
\hline \multicolumn{3}{|l|}{ ka bo mu } \\
\hline \multicolumn{3}{|l|}{ su ma } \\
\hline ye tia & & \\
\hline
\end{tabular}




\begin{tabular}{|l|l|l|}
\hline to twene /to kyene & & \\
\hline fa to ho & & \\
\hline
\end{tabular}

B. Please make a noun out of the following serial verbs. Also give the meaning of the noun. If there is no corresponding noun form, please write NONE. If you are not sure, please write NOT SURE.

\begin{tabular}{|c|c|c|}
\hline VERB FORMS & CORRESPONDING NOUN FORM & MEANING OF NOUN \\
\hline \multicolumn{3}{|c|}{ 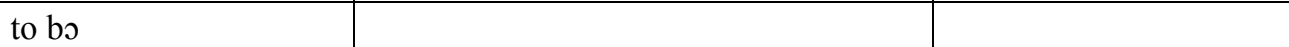 } \\
\hline \multicolumn{3}{|l|}{ fa hye } \\
\hline \multicolumn{3}{|l|}{ hwie gu } \\
\hline \multicolumn{3}{|l|}{ pia bo } \\
\hline \multicolumn{3}{|l|}{ tow wo } \\
\hline \multicolumn{3}{|l|}{ fa gu } \\
\hline \multicolumn{3}{|l|}{ noa ma } \\
\hline \multicolumn{3}{|l|}{ fa soma } \\
\hline \multicolumn{3}{|l|}{ ma hwe ase } \\
\hline \multicolumn{3}{|l|}{ fa ye } \\
\hline \multicolumn{3}{|l|}{ yع ma } \\
\hline \multicolumn{3}{|l|}{ fa bre } \\
\hline \multicolumn{3}{|l|}{ ma ko } \\
\hline \multicolumn{3}{|l|}{ fa ma } \\
\hline \multicolumn{3}{|l|}{ fa sie } \\
\hline fa to & & \\
\hline
\end{tabular}

C. Please make a noun out of the following serial verbs. Also give the meaning of the noun. If there is no corresponding noun form, please write NONE. If you are not sure, please write NOT SURE.

\begin{tabular}{|l|l|l|}
\hline VERB FORMS & CORRESPONDING NOUN FORM & MEANING OF NOUN \\
\hline di boro & & \\
\hline ka frafra & & \\
\hline pam sen & & \\
\hline ko foro & & \\
\hline ka kodu & & \\
\hline bisa ma & & \\
\hline da bre & & \\
\hline woro fa & & \\
\hline bre hunu & & \\
\hline nya kose & & \\
\hline te sere & & \\
\hline hu bo & & \\
\hline ko kyere & & \\
\hline pe ye & & \\
\hline
\end{tabular}




\begin{tabular}{|l|l|l|}
\hline fa hwe & & \\
\hline to pem & & \\
\hline
\end{tabular}

A. Please provide the serial verbs from which these nouns are derived and the meanings of the individual verbs. If there is no corresponding verb form, please write NONE. If you are not sure, please write NOT SURE.

\begin{tabular}{|c|c|c|}
\hline NOUN FORM & VERB FORMS & MEANING OF EACH VERB \\
\hline \multicolumn{3}{|l|}{ oyima } \\
\hline \multicolumn{3}{|l|}{ gyidie } \\
\hline \multicolumn{3}{|l|}{ nkoguo } \\
\hline \multicolumn{3}{|l|}{ sufre } \\
\hline \multicolumn{3}{|l|}{ mmotoso } \\
\hline \multicolumn{3}{|l|}{ fakye } \\
\hline \multicolumn{3}{|l|}{ mməguo } \\
\hline \multicolumn{3}{|l|}{ mmstoho } \\
\hline \multicolumn{3}{|l|}{ ntwatoso } \\
\hline \multicolumn{3}{|l|}{ nsohwe } \\
\hline \multicolumn{3}{|l|}{ okakyere } \\
\hline \multicolumn{3}{|l|}{ nkabom(u) } \\
\hline \multicolumn{3}{|l|}{ oyctia } \\
\hline \multicolumn{3}{|l|}{ mfatoho } \\
\hline awuakye & & \\
\hline
\end{tabular}

B. Please indicate acceptability of the following noun forms by writing $\underline{A}$ for $A C C E P T A B L E$ or $\underline{U}$ for UNACCEPTABLE in the ACCEPTABILITY column. If not acceptable, please write the correct form below in the far right column. If there is no acceptable form, please write NONE. If you are not sure, please write NOT SURE.

\begin{tabular}{|l|l|l|}
\hline NOUN FORM & ACCEPTABILITY & CORRECT FORM \\
\hline ntobo & & \\
\hline mfahye & & \\
\hline hwiegu & & \\
\hline mpiabo & & \\
\hline ntows & & \\
\hline mfagu & & \\
\hline nnoama & & \\
\hline mfasoma & & \\
\hline ntows & & \\
\hline omahwease & & \\
\hline ofaye & & \\
\hline oyema & & \\
\hline mfahy & & \\
\hline omaks & & \\
\hline ofama & & \\
\hline
\end{tabular}




\begin{tabular}{|l|l|l|}
\hline ofasie & & \\
\hline mfato & & \\
\hline
\end{tabular}

C. Please provide the serial verbs from which these nouns are derived and the meanings of the individual verbs. If there is no corresponding verb form, please write NONE. If you are not sure, please write NOT SURE.

\begin{tabular}{|c|c|c|}
\hline NOUN FORM & VERB FORMS & MEANING OF EACH VERB \\
\hline \multicolumn{3}{|l|}{ kahyenkodu } \\
\hline \multicolumn{3}{|l|}{ fameye } \\
\hline \multicolumn{3}{|l|}{ kokoboa } \\
\hline \multicolumn{3}{|l|}{ ntensere } \\
\hline \multicolumn{3}{|l|}{ koankobi } \\
\hline \multicolumn{3}{|l|}{ oworskawafabatire } \\
\hline \multicolumn{3}{|l|}{ brekyirihunuadec } \\
\hline \multicolumn{3}{|l|}{ oseadesyo } \\
\hline \multicolumn{3}{|l|}{ okafrafra } \\
\hline \multicolumn{3}{|l|}{ okoforobos } \\
\hline \multicolumn{3}{|l|}{ ahuabobirim } \\
\hline \multicolumn{3}{|l|}{ akokyereahene } \\
\hline \multicolumn{3}{|l|}{ pewoayeden } \\
\hline \multicolumn{3}{|l|}{ fawanihwe } \\
\hline \multicolumn{3}{|l|}{ sankotie } \\
\hline atoapem & & \\
\hline
\end{tabular}

Meda ase. Thank you for your time and consideration in filling out this questionnaire.

Please return this questionnaire to the person who gave it to you or send to:

Department of Linguistics

c/o Obadele Kambon

University of Ghana-Legon

Legon, Accra, Ghana, West Africa

\section{References}

Aikhenvald, A. Y. 2006. Serial verb constructions in a typological perspective. In Aikhenvald \& R.M.W. Dixon (eds.), Serial verb constructions: a cross-linguistic typology. New York, Oxford University Press. 1-87.

Aikhenvald, A. Y. and R. M. W. Dixon 2006. Serial verb constructions: a cross-linguistic typology. Oxford, Oxford University Press.

Baker, M. C. 1989. Object sharing and projection in serial verb constructions. Linguistic Inquiry 20. 513-553.

Balmer, W. T. and F. Grant 1929. A grammar of the Fante-Akan language. London, Atlantis Press. 
Bannerman, J. Y., D. E. K. Krampah, et al. 2011. Mfantse nkasafua na kasambirenyi nkyercase: Dictionary of Mfantse words and idioms. Tema, Center for Indigenous Knowledge Systems.

Boadi, A. K. 2005. Twi kasa mmara ne kasesos. Kumasi, Katawuri.

Bodomo, A. 2004. The syntax of nominalized complex verbal predicates in Dagaare. Studia Linguistica 58(1). 1-22.

Bodomo, A. 2006. On nominalizing the verbal complex in Dagaare and English. 11th Biennial Symposium on Linguistics: Inter-Theoretical Approaches ot Complex Verb Constructions. Rice University: Houston Texas: 1-17.

Bodomo, A. and M. v. Oostendorp 1994. Serial verb nominalisations in Dagaare. Washington, DC, ERIC Clearinghouse: 31.

Christaller, J. G. 1875. A grammar of the Asante and Fante language called Twi. Basel, Basel Evangelical Missionary Society.

Christaller, J. G. 1933. A dictionary of the Asante and Fante language called Tshi (Twi). Basel, Basel Evangelical Missionary Society.

Durie, M. 1997. Grammatical structures in verb serialization. In Alsina, A., J. Bresnan \& P. Sells (eds.), Complex Predicates. Stanford, CSLI Publications: 289-354.

Ghana, E. D. o. 1971. Twi nscm nkorenkore kyercwbea. Accra, Waterville Publishing House.

Givon, T. 1993. English grammar. Amsterdam, John Benjamins.

Givon, T. 2001a. Syntax: Volume 1. Amsterdam/Philadelphia, John Benjamins.

Givon, T. 2001b. Syntax: Volume 2. Amsterdam/Philadelphia, John Benjamins.

Hellan, L., D. Beermann, et al. 2003. Two types of serial verb constructions in Akan. In Delsing, L.O., C. Falk and H. Sigurrdsson (eds.), Festschrift for Christer Platzack. Lund Department of Scandinavian Languages, Lund University: 1-11.

Hiraiwa, K. \& A. Bodomo 2008. Object-sharing as symmetric sharing: Evidence from Dagaare. Proceedings of the 26th West Coast Conference on Formal Linguistics, Somerville, MA, Cascadilla Proceedings Project.

Kambon, O. 2012. Serial verb nominalization in Akan. PhD, University of Ghana.

Osam, E. K. 1994. Aspects of Akan grammar: A Functional Perspective. Ph.D., University of Oregon.

Osam, E. K., R. A. Duah, et al. 2011. The so-called postpositions in Akan: A reconsideration. Journal of West African Languages 38(2). 107-118.

Patton, M. Q. 2002. Qualitative research \& evaluation methods, SAGE Publications.

Schachter, P. 1974. A non-transformational account of serial verbs. Studies in African Linguistics Suppl. 5. 253-270.

Dr. Ọbádélé Kambon

University of Ghana - Legon

obkambon@ug.edu.gh
Received: 18 July 14

Accepted: 18 Apr 15

Revisions: 10 May 15 
